\title{
Construction of a Multiple English Teaching Mode Based on Cloud Technology
}

\author{
https://doi.org/10.3991/ijet.v13i08.9054 \\ Ying $\mathrm{Xu}$ \\ Tonghua Normal University, Dongchang, China \\ yingxuxy2008@163.com
}

\begin{abstract}
In order to explore the construction of multiple English teaching ("learner-centered and teacher-led" classroom teaching + autonomous learning + interactive learning + multiple evaluation) mode based on cloud technology, a teaching system and operation procedures of new English teaching model are designed based on cloud technology. The design is completed through the analysis of the construction of multiple teaching mode under cloud technology and the introduction to multiple English language teaching steps. In addition, the English teaching modes under the traditional English teaching are compared with those based on cloud technology. Finally, the application of multiple teaching mode under cloud technology is analyzed. The results showed that multiple English teaching mode under cloud technology perfectly complied with the English teaching under modern conditions. To sum up, the proposed method plays a significant role in promoting the English teaching mode, which is worthy of further study and utilization.
\end{abstract}

Keywords-Cloud technology; English teaching mode; mode construction

\section{Introduction}

In recent years, the Internet information age, represented by gradual progress of globalization and rapid development of cloud technology, has influenced many aspects of people's lives. At home and abroad, we can see that, the development of cloud technology has been applied into language teaching, and at the same time, this application is in line with evolving teaching theory and requirements. It is necessary to integrate cloud technology and traditional foreign language teaching resources, making full use of the advantages of the Internet era. We should integrate cloud technology with foreign language curriculum, meeting basic needs modern education.

\section{State of the art}

Bhattacharjee, S. et al. [1] pointed out that cloud computing was a technology used to describe a new class of network-based computing that took place over the Internet. When cloud technology was introduced along with mobile, it provided effec-tive 
service for the individual. The wide use of cloud technology had also brought unprecedented opportunities and challenges to the development of language teaching. Dubey, A. et al [2] pointed out that cloud technology had played an important role is promoting traditional English teaching to modern one in China. Nowadays, more and more researchers, experts and teachers have begun to pay attention to this, and actively carry out researches from different angles.

Since 1960s when cloud technology was applied into language teaching, it has attracted domestic and foreign researchers' attention. Tao, F. et al [3] explained that according to different research purposes, scholars had adopted a variety of research methods to study it from different angles. If the research of cloud technology teaching in 1980 and 1990s was still keen on technology support, after entering twenty-first Century, it turned to cognition, education, culture and other aspects. The long-term accumulated educational practice had prompted people to rethink the existing experience and rationally develop it, and then model them into a completely new teaching structure. Ye, Y et al [4] thought that because of differences in the research environment and paradigm, scholars at home and abroad had obtained different findings in different fields.

Udoh, E. [5] pointed out that in recent years, the proportion of teachers and students in foreign language classrooms was unbalanced due to the continuous enrollment expansion of domestic universities. The original teaching methods and educational means were unable to satisfy the changing teaching needs, and the traditional foreign language teaching was in urgent need of reforming. At the same time, the rapid development of cloud technology and its wide application in teaching field had become one of the important measures to promote the reform of our traditional foreign language teaching experience. Gerard, P. et al [6] pointed out that in China's reform and research experience on the application of cloud technology in foreign language teaching for thirty years, we can conclude the following characteristics, From the overall trend, the research process was in a steady development state, and the quantity and quality of achievements were increased year by year. From the research object, it was mainly in foreign language teaching for university students. Huh, E. et al [7] explained that the college English teaching for non-English majors occupied the largest proportion. From the research method, early it was mainly on theoretical exploration, and in recent years, the proportion of empirical research relating to the test of practice increased year by year. In addition, research and design became more rational. N Schneider, S et al said that from the perspective of research content, there was a wide range of topics, and the most hot topics included the support theory research integrating cloud technology and foreign language teaching, analysis of advantages and disadvantages of multimedia aided teaching, the positioning of teachers' and students' roles, and the specific course (intensive reading, listening and speaking, translation, reading, literature and writing) teaching mode and teaching strategies study.

Pawlish, M. J. et al [9] thought that the design idea of multiple English teaching mode with cloud technology was the establishment of course teaching mode depending on a web, with text, pictures, audio and video as the main interactive media, network teaching as platform, and email and online chat tools as the main interactive 
means. In the entire teaching process, the teaching situation, collaborative learning and conversation and other elements are used for learning environment design, and the classroom teaching mode of "learner centered and teacher leading" is established. At the same time, through analyzing learner's background knowledge, language proficiency and cognitive level, we establish learning resource base that can meet the needs of different levels of learners. In addition, by setting specific tasks based on a particular subject, we establish self-study after class under the guidance of teachers, encourage learners to use the resources database to complete tasks through cooperation between teachers and students, as well as students and students.

Liu, Z. [10] pointed out that a green or energy efficient solution were supported for data centers that maintain computers and peripherals to serve organizations. Traditionally, data centers catered to all operations using in-house servers. Cloud technology provides alternatives to outsource operations heading towards greenness.

In view of the teaching methods and education methods mentioned in the introduction, based on the research experience of the above documents, this paper proposed the application of cloud technology in foreign language teaching. The innovative cloud technology is used English language teaching studies, which conforms to the teaching requirements and satisfies different levels of teaching needs, and reforms and innovates existing foreign language teaching models. Full details are given below.

\section{Method}

\subsection{Construction of multiple teaching model under cloud technology}

The author constructs the multiple English interactive teaching mode under the cloud technology. The definition is in the guidance of constructivist learning theory and interactive teaching concept, relying on cloud technology, taking the enhancement of learners' affective and cognitive structure as the goal, and the specific "task" as the starting point, we establish multiple English interactive teaching mode characterized by "learners as the center, guided by teachers" "classroom teaching + independent learning after class + interactive aid + multiple evaluation". In this mode, the learner is the active builder of language knowledge and subject knowledge meaning; teachers are organizers, guides and facilitators for learning activities, and they help students to complete self-construction of knowledge by using appropriate teaching strategies. The specific "task" is the starting point, and the learners, through design and implementation of specific tasks, not only complete perfect combination between subject knowledge and comprehensive ability of using language (cognitive goal), but also enhance the independent learning ability, cooperation ability and the inquiry ability of knowledge (emotional target). Multimedia network is not only the tool for the creation of situation and knowledge transfer, but also the media for the multiple interactive communication and cooperation between teachers and students after class. Moreover, it is the cognitive tool for auxiliary learners to complete autonomous learning and collaborative inquiry. The rich network resources are the main learning con- 
tent for learners, and the important guarantee for students to realize independent knowledge construction.

\subsection{Steps to carry out multiple English teaching}

Firstly, we should construct the model of English classroom teaching under the cloud technology. To carry out English classroom teaching under the network environment, teachers should firstly analyze the needs of unit teaching, so as to determine the necessity of carrying out teaching activities for a specific content. This can be achieved through online investigation or access to the learner's electronic files. At the same time, we should also investigate learners' characteristics, such as related knowledge background, learning motivation, learning goals, learning strategies etc., so as to determine the teaching objectives of the unit. The second step is that teachers determine the content of teaching according to the objectives of unit teaching and learners' needs and can use network resources to supplement or reduce the teaching contents properly. The third step is that, teachers should clarify the teaching objectives and the specific criteria for the evaluation of learners in the course of teaching, including the content, form and standard of the test. Fourthly, design the classroom teaching strategy, including the form and order of the teaching content, the arrangement of teaching activities and so on. Fifthly, develop the teaching auxiliary materials. Multiple teaching is set up for learners with certain professional knowledge. Teachers can compile or select appropriate materials according to learners' characteristics to supplement classroom teaching.

Secondly, we should establish the model of autonomous English learning under the cloud technology. In this study, we strive to take "tasks" as the starting point and construct independent learning models under the instruction of teachers as a useful supplement to the classroom teaching. Constructivist learning theory holds that language learning is a process of positive experience, and learners construct objective meaning through observation, practice, exploration and reflection. This study encourages learners to identify research projects based on their professional fields, take teamwork as a form, make full use of network resources, and complete simulation learning projects slightly higher than the existing level. In this process, cloud technology enables communication between teachers and students, between students and students, between human and machine, between students and learning content to break the traditional limit of time and space. As a result, it provides technical support and guarantee for project's implementation, but also provides space and place for the learners to establish knowledge meaning construction.

Thirdly, we should construct a multiple dynamic evaluation system for English teaching. Constructivist learning theory holds that network learners need to evaluate their learning processes and results by self-diagnosis and self-reflection. Based on this theory, formative assessment method focuses on providing feedback information to learners' learning process, and evaluates their development in learning motivation, learning strategies and emotional attitudes. In view of this, the author constructs the multiple dynamic evaluation system of English teaching under the cloud technology. The so-called "multiple" refers to the diversification of learners' evaluation contents, 
including learning attitude, class performance, multiple language skills, project completion and so on. The so-called "dynamic" refers to that learners' evaluation is not a hammer of the summative evaluation results, but stage learning effect. The specific form of the evaluation system is "diagnostic evaluation + formative evaluation + summative evaluation", which includes establishing students' learning portfolios, teachers' classroom observation records, and periodical assessment results. In this process, teachers should make full use of the network teaching management platform to supervise students' learning progress, and carry out diagnostic evaluation and phased tests through online tests.

Fourthly, we should set up a multiple English teaching resource library of cloud technology. The rich network resources can not only be a useful supplement to classroom teaching material, but also provides help for students' autonomous learning and personalized learning after class, and it is an important guarantee for developing multiple English teaching. Through network, we make a targeted collection of teaching materials at home and abroad in related fields and establish online teaching resource database so that we can use half the effort to double the teaching practice. Resource library construction has two channels. One is the cooperation between foreign language teachers and professional teachers, to jointly develop teaching materials suitable to the professional learners' special knowledge needs and language knowledge level. It not only ensures the authority of the professional teaching resources, but also guarantees the accuracy of the language. The other is that students can be encouraged to participate in the construction of the resource base. In this process, teachers can give proper guidance and monitoring, which not only enriches the contents of resources, but also helps students to build knowledge actively.

\section{$4 \quad$ Results}

\subsection{New mode construction of English teaching based on cloud technology}

The English teaching can construct the English classroom teaching model of "network environment + classroom teaching", as shown in Figure 1.

The network teaching environment in this model refers to the environment of learning through network online, and the classroom teaching is carried out in the traditional way. The essence of it is to introduce cloud technology into English classroom teaching, optimize the teaching process, and emphasize the combination of autonomous learning and classroom teaching. The teaching content includes five aspects: English listening, speaking, reading, writing and translating. These five aspects of teaching can be organized in a separate way and can also be carried out in an integrated way.

According to the teaching practice of these years, English teaching in China is basically integrated with the skills of listening, speaking, reading, writing and translating. In this way, the content of teaching will be more abundant and the form of teaching is more flexible. Under the traditional teaching environment, the emphasis of teaching can be placed on reading and writing training, while in cloud technology 
teaching, we can highlight listening and speaking teaching and give consideration to reading. The teaching content is supported by the corresponding teaching materials, and the teaching methods can be selected according to the teaching environment. Teaching management can be achieved through educational administration, teachers and related software.

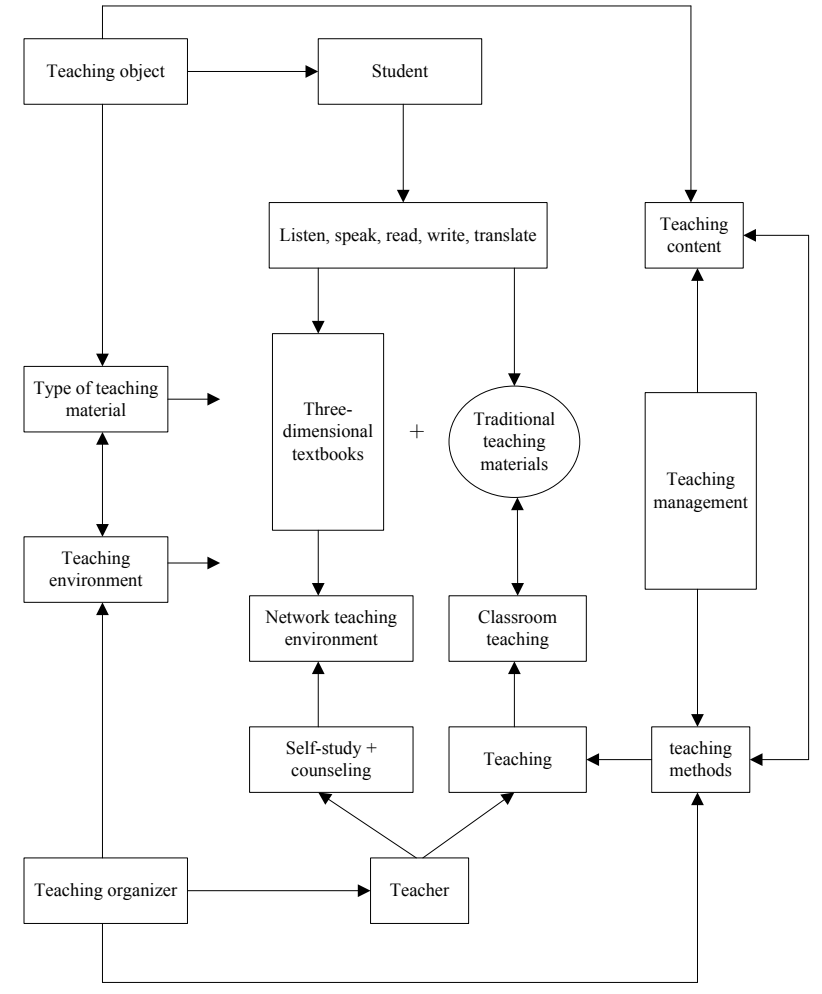

Fig. 1. English classroom teaching mode based on cloud technology

In the colleges with complete modern teaching conditions and facilities, the English teaching can fully carry out the teaching on conditions based on cloud technology. Each of the English classroom can be combined with the teachers' explanation and use of the network. For the universities with relatively backward modern teaching conditions or facilities, English teaching can be divided into two parts. One is to make knowledge teaching and learning ability cultivation in the traditional classroom, and the other is to conduct language skills training and quality expansion in the network multimedia classroom.

This new model is characterized by the assistant teaching of cloud technology, and the three-dimensional teaching material is the carrier, which fully embodies sev-eral characteristics.

First of all, it highlights the advantages of cloud technology teaching. In the teaching, through sound, images, text, and animation, it increases the stimulation of stu- 
dents' sensory organs, making the content vivid, three-dimensional, and imaged. As a result, it not only improves the students' learning interest, and efficiency, but also simplifies the language points difficult to understand through the multimedia means, more conducive to the students' understanding and memory. The network provides a more authentic language environment for students. Through the network, students can not only enjoy the excellent English movies and TV programs, but also use social networks, such as QQ, emails and native speakers for verbal and written communication, which is of great help to improve students' language ability. Moreo-ver, it can comprehensively improve students' listening, speaking, reading, writing and translation abilities, making the boring English learning funny. In local or auton-omous learning center, students will not be limited by time, but make full use of open, diversified and authentic language learning environment. According to the teaching contents and tasks, as well as their own needs and the level of English, students can choose appropriate learning content, and adopt suitable schedule and methods for personalized learning.

Secondly, the combination of network teaching environment and classroom teaching is a new type of teaching model. This teaching mode, which integrates stu-dents' autonomous learning and teacher guided teaching, better reflects the roles and tasks of teachers and students in English teaching process. Teachers are dominant and students are the main body. Autonomous learning is not free learning to leave teachers, but to achieve the necessary learning tasks under the guidance of certain teaching objectives, realize the preset learning results, and use cloud technology to carry out the learning process. The setting of teaching objectives and the learning results, the solution of the related problems, and the application of the learning strategies and methods should be guided by the teachers. In classroom teaching, teachers should teach students how to carry out autonomous learning. They should focus on the guidance of learning methods and strategies and pay attention to solving problems and difficulties. Compared with the traditional classroom teaching method of single teaching mode, this mode makes classroom teaching form diversified and individualized so that language teaching tends to be rationalized.

\subsection{Teaching system of new English teaching mode based on cloud technology}

A new model of English teaching under the condition of cloud technology is not the negation or subversion of traditional teaching mode, but is precisely to make up for and perfect the deficiency of the traditional teaching mode by the use of modern information technology. In the meanwhile, the valuable teaching method and experience in traditional teaching mode can be continued, achieving the combination of two kinds of teaching modes with the coexistence of traditional and modern ways, and the two complement each other.

In the new mode, the teaching system is composed of two parts. One is the traditional classroom teaching system, and the other is the network teaching system based on cloud technology. The former generally includes 3 elements, teachers, students and textbooks, and the latter includes the media. The English teaching in the traditional mode has been always used in China for foreign language teaching, and it will proba- 
bly continue to be used. People are very familiar with this mode, so this article will not further explain this, but to further discuss the network teaching system under cloud technology.

The network teaching system is mainly composed of teaching modules and some auxiliary modules, which is the prerequisite and requirement for the development of network teaching. Referring to the relevant information, the English teaching system under the cloud technology can be made up of the following subsystems.

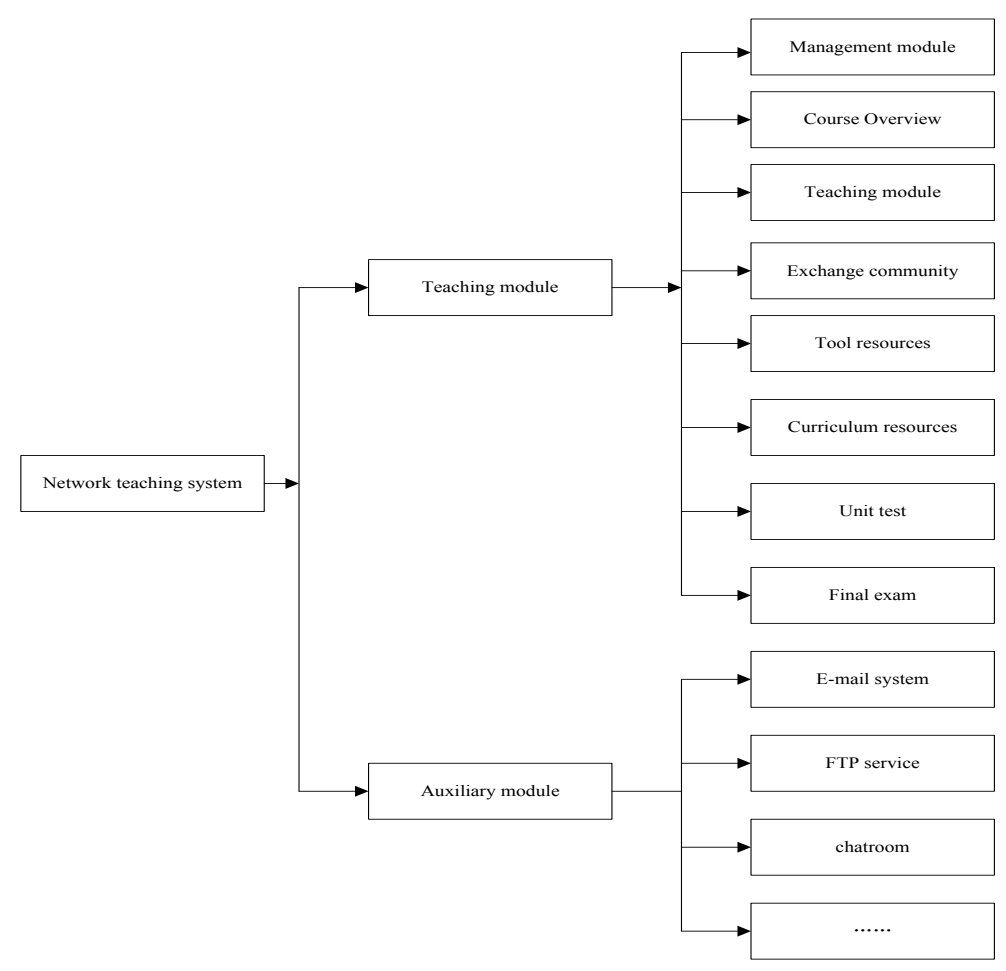

Fig. 2. Schematic diagram of teaching system based on cloud technology

Management module is the main guarantee for smooth development of network teaching. It should include all aspects of teacher and student accounts, learning records, teaching management and management. It's an important way for teachers to supervise and check students' autonomous learning.

A general survey of the course is a specific description and explanation of this course's teaching plan, goals and requirements, learning methods and strategies, testing and assessment, answering questions and solving puzzles etc., which is a part that students should have a clear understanding before carrying out autonomous learning.

Teaching module is the main content of the network teaching system, which should include all the teaching contents, involving five aspects of listening, speaking, reading, writing and translation in English teaching. The teaching contents and tasks selected by the teachers will be presented to students through PowerPoint lectures, 
Word documents, pictures, audio, video, animation, and web pages. Teaching will no longer be restricted in the face-to-face communication between teachers and students. Students complete tasks through accessing and browsing the teaching home page. Students are not restricted by time, space and place. Only by visiting and browsing the teaching homepage, they can learn at any time and ant place.

Tool resources mean that in order to facilitate the students to use the relevant teaching software, we can integrate with some common audio, video, image, decompression, recording, electronic dictionaries and other necessary tools in the network learning environment, so that students will not delay learning because of the tools problems in the use of network resources.

Communicate community includes the discussion between students and teachers as well as among students. Teachers can put forward questions in advance, and students respond according to the requirements. They can also raise questions in their study, to which teachers give answers. The discussion between students can be viewpoints or questions put forward by individual students, which can lead to other students' discussions. They can be discussed at random according to related topics or can be discussed in depth for a topic or theme.

For curriculum resources, the content of classroom teaching is limited, and the capacity of teaching material is also limited. In order to enable students to better expand knowledge and broaden their horizons, we should add all kinds of learning materials closely related to learning topics in this module. This can better meet the needs of the students' individualized learning.

Unit test is to effectively investigate and evaluate students' learning situations in English at ordinary times and avoid some students' learning only for tasks. We can make use of characteristics that the Internet is not limited by time and space, so that students can do unit tests autonomously. This can not only supervise students' progress according to the requirements of relevant teaching plans, but also test students' phased learning achievements. In addition, it facilitates teachers to make adaptive adjustment according to students' learning situation.

Final exam is a check of the overall learning effect of a student in a teaching stage. It can be randomly selected from the question bank consisting of related topics of teaching content, and teachers can choose the type of questions according to the requirements of assessment and determine the scores.

Above are basic parts of the English teaching system network, and we can complete the teaching tasks through the above functions. In order to extend the dimension and space of English teaching, conditional colleges and universities can also provide auxiliary modules, including email services, FTP services, chat rooms, pen pal hurdles and other functions, so that students can expand their English learning space to out of school or even abroad.

\subsection{Operation program of new mode of English teaching based on cloud technology}

After making clear the composition of the network teaching system, the operating procedures of this teaching mode are discussed below. The students' learning process 
is shown below. We should first of all be familiar with the basic characteristics and the requirements of the course learning of the teaching model under the cloud technology. Then, the learning content is self - learned according to the unit structure on the network, and the unit test is used to detect the mastery of the content. If students fail to pass the unit test, they are supposed to continue to learn and consolidate until they pass the requirements of the course. If they pass the unit test successfully, they can accept the teachers counseling. After that, the students can start a new unit to continue learning and complete the teaching content in this order.

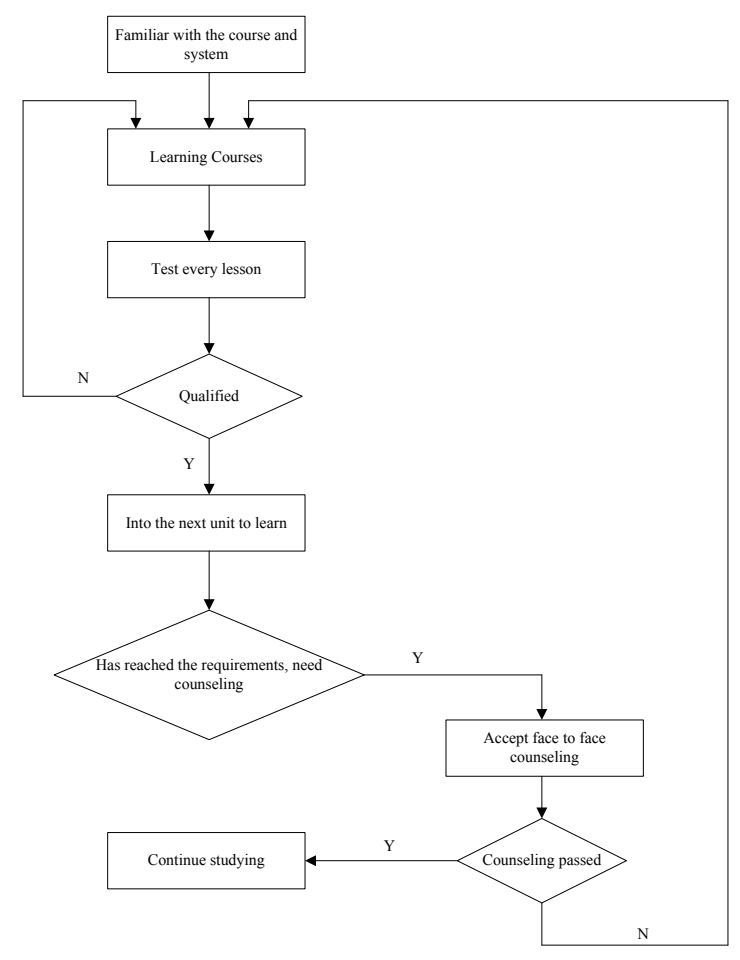

Fig. 3. English teaching process based on cloud technology

In the teaching system, teachers and students should firstly have user accounts with different privileges. This is the premise of teaching under the network condition. In the teaching, teachers and students log into the system through their own accounts. The time, content and process and other factors of students' learning are recorded by the management system.

The second is teachers' lessons preparation and teaching arrangements. Teaching design, learning contents and related learning materials are embedded in the network English teaching platform in a multi-media and three-dimensional way. Teachers make specific arrangements and requirements for the implementation of the holistic 
teaching according to the teaching plan. This is a very important link in the implementation of English teaching under the Internet.

Then, it is the individualized self-learning process of the students. This is the most critical part of English teaching in the whole network. Under the premise of the relevant teaching conditions and facilities, students can learn through online network teaching platform. If it is arranged in a formal network class, the students can study at specified time and place. If it is outside the classroom, students can enter the network system at anytime and anywhere. Students can arrange their learning in accordance with the teaching schedule and requirements set by teachers and teaching systems and can also decide their learning according to their specific situations.

\subsection{Comparison between the traditional English teaching model and the English teaching model under the cloud technology}

Under the condition of cloud technology, people can transfer and share knowledge through an independent and equal relationship and can apply this idea to every field of teaching. The penetration of cloud technology into the teaching field has become a supplement and extension of classroom teaching, which helps to pro-mote the transformation of teaching mode and educational concept, and promote the development of education. It is foreseeable that cloud technology enters education and approaches teachers, which not only changes the traditional education and teaching mode, but also promotes the development of education to a certain extent. Cloud technology brings new ideas for English teaching, and it plays an advantage in constructing education information and improves the efficiency in the teaching field. In short, the English teaching mode under cloud technology has broken the traditional "teachercentered" teaching mode, making the teaching activity process and organizational form showing a totally new look. We can compare the two patterns in the chart form below.

Table 1. Comparison of Traditional English Teaching Model and English Teaching Model under Cloud Technology

\begin{tabular}{|l|l|}
\hline \multicolumn{1}{|c|}{ Traditional English teaching mode } & \multicolumn{1}{c|}{ English Teaching Model under Cloud Technology } \\
\hline Textbooks as the authority of teaching materials & Visit blogs, podcasts and more \\
\hline Learning content is single & All kinds of network resources sharing \\
\hline Preaching teaching (teacher to student group) & $\begin{array}{l}\text { Interactive teaching (interaction between teacher and } \\
\text { student, student and student, teacher and teacher) }\end{array}$ \\
\hline Starting from facts, the teacher is an expert & $\begin{array}{l}\text { Based on learning and exploration, the teacher plays a } \\
\text { guiding role }\end{array}$ \\
\hline Learn fixed words, grammar knowledge, etc. & Emphasis on students' ability to innovate \\
\hline Emphasis on learning outcomes & Emphasis on teaching process \\
\hline To grasp the vocabulary, grammar as the criterion & $\begin{array}{l}\text { Judgments based on comprehensive ability of listening } \\
\text { and speaking as the standard }\end{array}$ \\
\hline
\end{tabular}




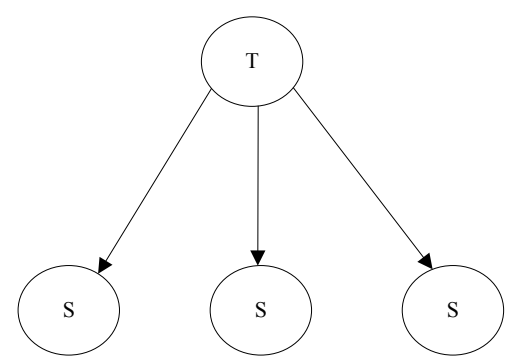

Fig. 4. Teacher and student group exchange in traditional mode

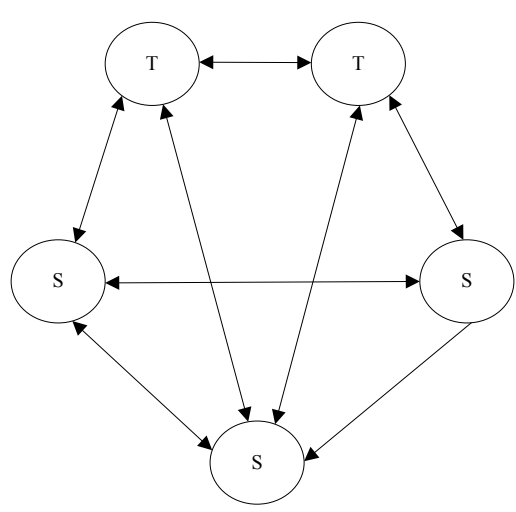

Fig. 5. Teachers and students under the cloud technology have personal communication

\subsection{Application of multiple English teaching modes based on cloud technology}

Taking the class blog as an example, this paper expounds the multiple English teaching models based on cloud technology. The major application is shown as follows.

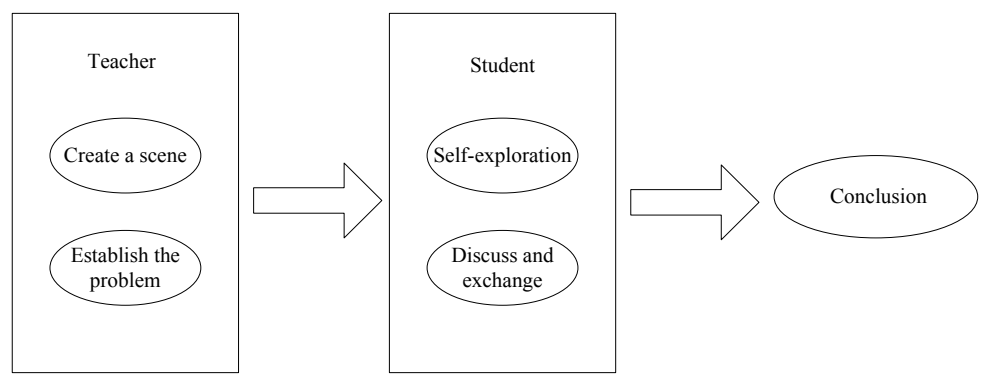

Fig. 6. Blog exchange for students 
Blogs provide more evaluation, reflect their understanding of some problems, and provide more extensive background information. Some scholars start to think about these problems through blog logs. These views may be crude, and they express these thoughts, and then post a follow-up opinion on blog. In this process, they can express what books they have read recently, whose books they have read, and what opinions they have heard in blogs. In this way, the reader understands not only the static and current views, but also grasps experts' thought process, as shown in Figure 7.

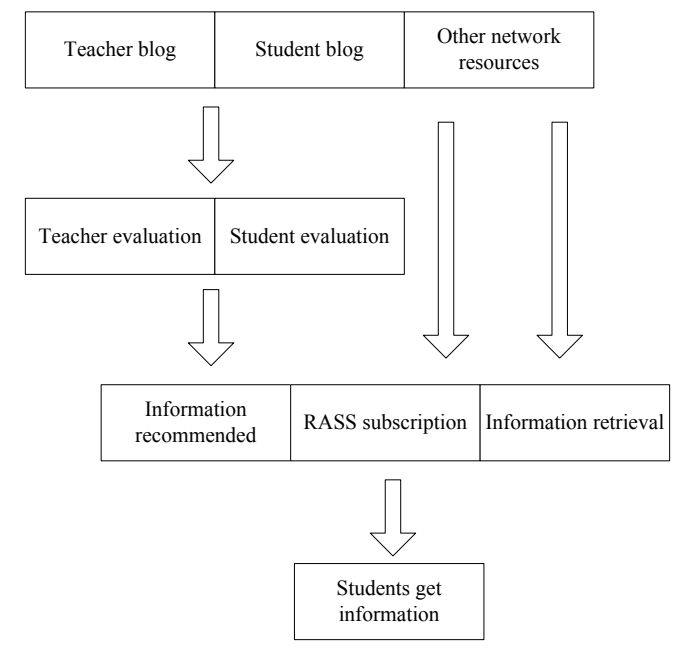

Fig. 7. Two-way interaction between teacher and student

For opinions of teachers or on books, students can express their understanding of these questions through the way of reply, which does not require the unity of opinions, but requires the pertinence and independence of opinions. In addition, a number of different topics can be set up in the process of the course setting, allowing students to freely choose the topics that they are interested in.

\section{Conclusion}

The English teaching model under cloud technology is a new teaching model, and it is a new direction for the reform and exploration of public English teaching in colleges and universities. It sets, based on modern teaching theory as the guidance, modern information technology as the guarantee, and cultivating students' autono-mous learning ability and improving students' ability to use English language as the basic goals. It also takes the set network teaching and traditional teaching advantages as its characteristics, to integrate modern educational technology with modern educational concept. At last, the following conclusions can be drawn.

Firstly, the new model of English teaching in cloud technology delivers and shares knowledge through an autonomous, equal relationship and can apply this concept to 
all areas of teaching. Infiltrating the cloud technology into the teaching field has become a supplement and extension of classroom teaching, which helps to promote the reform of the teaching model, education concept and promote education development.

Secondly, with building a real natural language context as the characteristic, it can overcome the problems and shortcomings in the current English teaching mode, students' difference, teachers' ideas, teacher strength and other aspects. The main factors that restrict the development of English teaching are focused on,

Thirdly, it is also in line with the learning view of constructivism studying. Theoretically speaking, it is fully consistent with English teaching under modern conditions. As a result, the multiple English teaching mode based on cloud technology is worth promoting in English teaching.

\section{References}

[1] Bhattacharjee, S., Bhattacharjee, S., \& Sinha, M. K. Asian journal of multidisciplinary studies awareness on cloud and mobile technology based services among central university library users of northeast India: a case study. Asian Journal of Multidisciplinary Studies. 2014, vol. 3(3), pp. 118-123.

[2] Dubey, A., Santoso, S., Cloud, M. P., \& Waclawiak, M. Ieee power and energy technology systems journal determining time-of-use schedules for electric vehicle loads: a practical perspective. IEEE Power and Energy Technology Systems Journal, 2015, vol. 2(1), pp. 1220. https://doi.org/10.1109/JPETS.2015.2405069

[3] Tao, F., Zhang, L., Nee, A. Y. C., \& Pickl, S. W. Editorial for the special issue on big data and cloud technology for manufacturing. International Journal of Advanced Manufacturing Technology, 2016, vol. 84(1-4), pp. 1-3. https://doi.org/10.1007/s00170-016-8495-6

[4] Ye, Y., Hu, T., Zhang, C., \& Luo, W. Design and development of a cnc machining process knowledge base using cloud technology. International Journal of Advanced Manufacturing Technology, 2016, pp. 1-13.

[5] Udoh, E. Technology acceptance model applied to the adoption of grid and cloud technology. International Journal of Grid \& High Performance Computing, 2012, vol. 4(1), pp. 120. https://doi.org/10.4018/jghpc.2012010101

[6] Gerard, P., Kapadia, N., Chang, P. T., Acharya, J., Seiler, M., \& Lefkovitz, Z. Extended outlook: description, utilization, and daily applications of cloud technology in radiology. Ajr American Journal of Roentgenology, 2013, vol. 201(6), pp. 809-811. https://doi.org/10.2214/AJR.12.9673

[7] Huh, E. N., \& Abawajy, J. Emerging sensor-cloud technology for pervasive services and applications. International Journal of Distributed Sensor Networks, 2014, vol. 1, pp. 1-3.

[8] Schneider, S., \& Sunyaev, A. Determinant factors of cloud-sourcing decisions: reflecting on the it outsourcing literature in the era of cloud computing. Journal of Information Technology, 2016, vol. 31(1), pp. 1-31. https://doi.org/10.1057/jit.2014.25

[9] Pawlish, M. J., Varde, A. S., Robila, S. A., \& Aljawarneh, S. The greening of data centers with cloud technology. International Journal of Cloud Applications \& Computing, 2015, 5(4), pp. 1-23. https://doi.org/10.4018/IJCAC.2015100101

[10] Liu, Z. A multi-index measurement model of English classroom teaching level in colleges and universities based on fuzzy system theory. Journal of Computational and Theoretical Nanoscience, 2017, vol. 14(1), pp. 46-50. https://doi.org/10.1166/jctn.2017.6122 
Paper-Construction of a Multiple English Teaching Mode Based on Cloud Technology

\section{$7 \quad$ Author}

Ying Xu, Tonghua normal university, Dongchang, China. The main research direction is foreign language literature (yingxuxy2008@163.com)

Article submitted 13 March 2018. Resubmitted 20 April 2018. Final acceptance 23 June 2018. Final version published as submitted by the author. 